\title{
Compressibility of the fluid
}

\author{
Jana Jablonská ${ }^{1, a}$ \\ ${ }^{1}$ Department of Hydromechanics and Hydraulic Equipment, Faculty of Mechanical Engineering, VŠB-Technical \\ University of Ostrava, 17. listopadu 15, 70833 Ostrava, Czech republic
}

\begin{abstract}
The presence of air in the liquid causes the dynamic system behaviour. When solve to issue of the dynamics we often meet problems of cavitation. Cavitation is an undesirable phenomenon, since it causes a disruption of the surrounding material and material destruction. Cavitation is accompanied by loud sound effects and reduces the efficiency of such pumps, etc. Therefore, it is desirable to model systems in which the cavitation might occur. A typical example is a solution of water hammer.
\end{abstract}

\section{Introduction}

In solving dynamics of hydraulic systems we often encounter the problem with cavitation. Cavitation is an undesirable phenomenon that we are trying to prevent. Cavitation depends on the liquid used in the hydraulic system. Liquids - hydraulic fluids are typical of its air content. The air in the fluid occurs in two forms dissolved and undissolved. Dissolved air according to the literature [4] ia controled by Henry's law, its release is complex and difficult to describe action. If we consider the fluid flow with undissolved air it is a flow of mixture - water - air.

\section{Compressibility of the fluid}

Compressibility of the fluid is character to shrink in volume when increasing the external pressure. It is expressed by coefficient of compressibility $[2,7]$

$$
\delta=\frac{1}{K}=-\frac{1}{V}\left(\frac{\partial V}{\partial p}\right)_{T=k o n s t}=-\frac{\Delta V}{V} \cdot \frac{1}{\Delta p}
$$

where $\mathrm{V}$ is original volume, $\Delta \mathrm{V}$ is change of volume caused by change in pressure $\Delta \mathrm{p}$ at constant temperature.

Therefore we can write

$$
\Delta V=V-V_{0}, \Delta p=p_{0}-p
$$

From equation 1 and 2 can be deduced

$$
V_{0}=V-\Delta V=V(1-\delta \cdot \Delta p)
$$

Fluid density after compression is given by

$$
\rho_{0}=\frac{m}{V_{0}}=\frac{m}{V(1-\delta \cdot \Delta p)}=\frac{\rho}{1-\delta \cdot \Delta p}
$$

Thereof

$$
\rho=\rho_{0}\left(1-\frac{\Delta p}{K}\right)
$$

\section{Determining the modulus of elasticity of liquid}

The modulus of elasticity of water is generally in the literature determines the value of $2.1 \cdot 10^{9} \mathrm{~Pa}$ under normal conditions, which corresponds to theory 1 (see Figure 3 ). The modulus of elasticity is dependent on pressure, temperature (see Figure 1) and a significant effect on it has a content of undissolved (free) air in the liquid. The undissolved air greatly reduces the modulus of elasticity in the liquid. You can think of it as the air in the form of bubbles in the liquid. [2, 3, 7, 8, 9]

Liquid containing undissolved air (free) is no longer homogeneous environment and is a suspension of gas (air) in the liquid (water) Module compressibility of air under normal conditions is $1.4 \cdot 10^{6} \mathrm{~Pa}[2,4]$, it is three orders of magnitude less than the value for water.

\footnotetext{
a Jana Jablonská: jana.jablonska@vsb.cz
} 

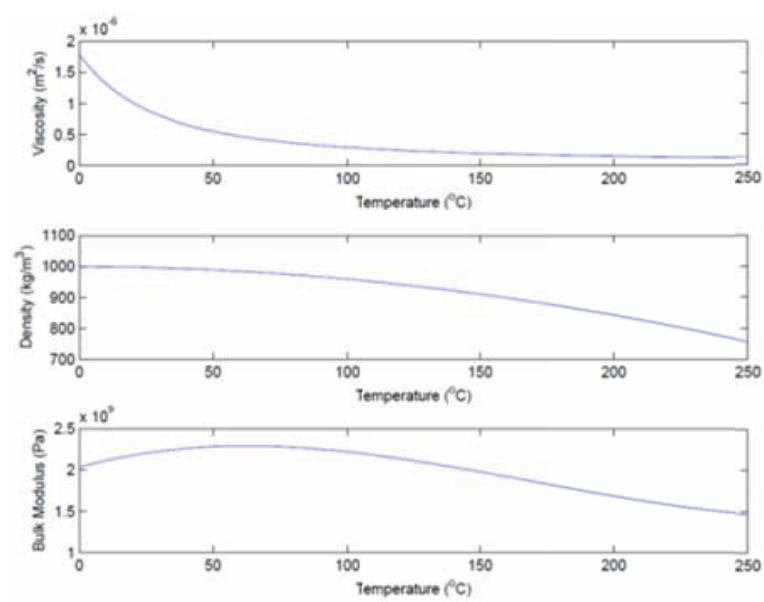

Fig. 1. Basic properties of water depending on temperature [3]

\subsection{Determining modulus of elasticity from the experiment}

One way of precise identification modulus of liquid elasticity (suspension water - air) in the system is measurement. The graph of pressure course in the hydraulic shock can be deducted value of the period $t_{p}$ (see Figure 2). [1]

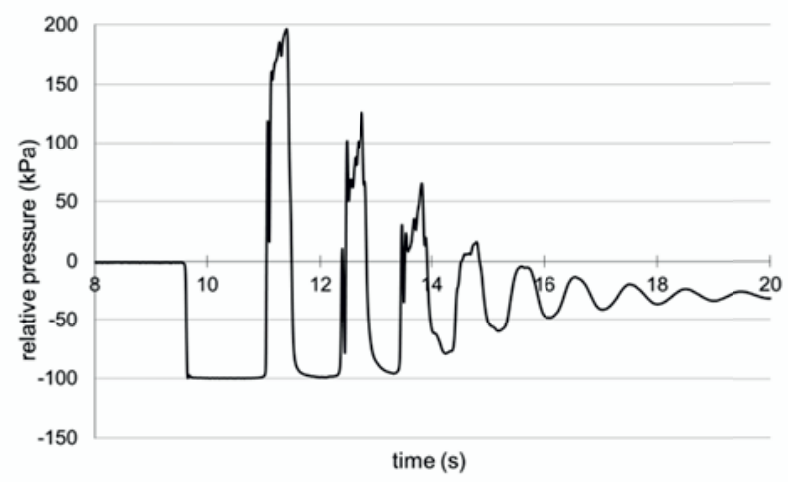

Fig. 2. Record of pressure during hydraulic shock (valve at the beginning of pipeline)

From period can be determined the time course of wave $T$

$$
T=\frac{t_{p}}{2}=\frac{0.934}{2}=0.467 s
$$

Spread velocity of shock wave to be calculated from length of piping $l=58.28 m$ (pump - closing valve) and from the period

$$
a_{S, \exp }=\frac{2 \cdot l}{T}=\frac{2 \cdot 58.28}{0.467}=249.59 \mathrm{~m} \cdot \mathrm{s}^{-1}
$$

Module of liquid compressibility

$$
\begin{aligned}
& a_{s, \exp }=\sqrt{\frac{K}{\rho}} \quad \Rightarrow \quad K=a_{s, \exp }^{2} \cdot \rho \\
& K=249.59^{2} \cdot 998=62.172 \cdot 10^{6} \mathrm{~Pa}
\end{aligned}
$$

To determine the theoretical modulus of liquid elasticity for the tube with fluid in the literature indicates spread velocity of pressure waves in the range $a_{s}=(20 \div 800) m \cdot s^{-1}[2,5]$.

Table 1. Measured and calculated values.

\begin{tabular}{|l|c|c|c|}
\hline & $\begin{array}{c}\text { Experimental } \\
\text { values }\end{array}$ & \multicolumn{2}{|c|}{ Literature values } \\
\hline $\begin{array}{l}\text { Run time of wave } \\
T(s)\end{array}$ & $\mathbf{0 . 4 6 7}$ & - & - \\
\hline $\begin{array}{l}\text { Act. Speed of } \\
\text { sound } a_{s}\left(\mathrm{~m} \cdot \mathrm{s}^{-1}\right)\end{array}$ & 249.59 & $\mathbf{2 0}$ & $\mathbf{8 0 0}$ \\
\hline $\begin{array}{l}\text { Modulus } \\
\text { compressibility } \\
K(P a)\end{array}$ & $62.172 \cdot 10^{6}$ & $0.399 \cdot 10^{6}$ & $638.7 \cdot 10^{6}$ \\
\hline
\end{tabular}

\subsection{Determining modulus of elasticity from RLC resistances}

Another possibility is to determine the modulus of liquid elasticity with the inclusion of pipes 'wall elasticity (without considering air) [7].

$$
\begin{aligned}
\frac{1}{K}=\frac{1}{K_{\text {voda }}}+\frac{d}{E \cdot s} & =\frac{1}{2.1 \cdot 10^{9}}+\frac{0.029}{700 \cdot 10^{6} \cdot 0.005} \\
K & =114130435 P a
\end{aligned}
$$

\subsection{Determining modulus of elasticity with air - theory 2}

If from formula (1) generally applies that

$$
K=-V \frac{d p}{d V}
$$

For volume of mixure must then apply

$$
V=V_{k}+V_{g}
$$

Where $V_{k}$ is liquid volume, $V_{g}$ is gas volume (air) at reference (atmospheric) pressure.

If the volume fraction of gas $\alpha_{p}$ (air) in a liquid is defined as

$$
\alpha_{p}=\frac{V_{g}}{V_{k}} \quad \Rightarrow \quad V_{g}=\alpha_{p} \cdot V_{k}
$$

Than volume fraction depends on the pressure and from equation can be deduced

$$
\alpha_{p}=\alpha\left(\frac{p_{r e f}}{p_{r e f}+p}\right)^{1 / n}
$$


After substituting equation (12) and (13) to equation (11) applies

$$
\begin{aligned}
& V=V_{k}+\alpha_{p} \cdot V_{k}=V_{k}\left(1+\alpha\left(\frac{p_{r e f}}{p_{r e f}+p}\right)^{1 / n}\right) \\
& V=V_{k}\left(1+\alpha_{p}\right)
\end{aligned}
$$

After substituting equation (14) to equation (10)

$$
\begin{aligned}
& K=-V_{k}\left(1+\alpha\left(\frac{p_{r e f}}{p_{r e f}+p}\right)^{1 / n}\right) \frac{d p}{d V} \\
& K=-V_{k}\left(1+\alpha_{p}\right) \frac{d p}{d V}
\end{aligned}
$$

After derivation can be deduced for modulus of liquid elasticity form

$$
K=K_{r e f} \cdot \frac{1+\alpha \cdot\left(\frac{p_{r e f}}{p_{r e f}+p}\right)^{1 / n}}{1+\alpha \cdot K_{r e f} \frac{p_{r e f}^{1 / n}}{n \cdot\left(p_{r e f}+p\right)^{n+1}}}
$$

Where $p_{\text {ref }}=p_{0}$ is atmospheric pressure, $\alpha$ is relative gas content at atmospheric pressure, $n$ is gas specific heat ratio.

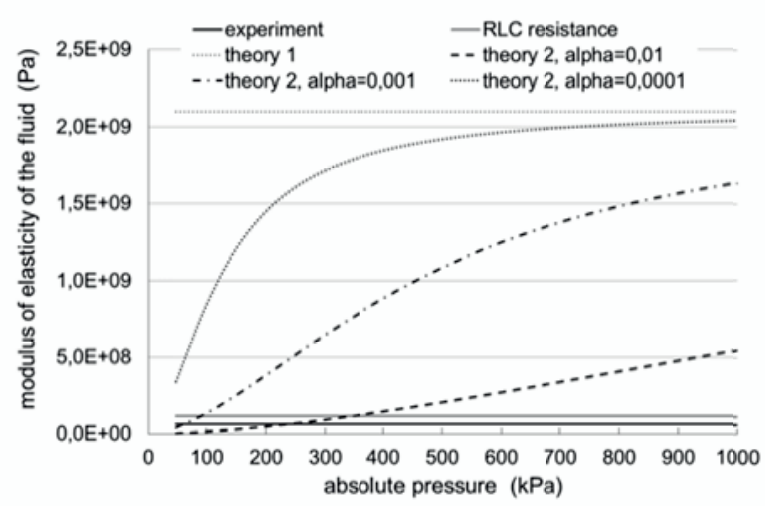

Fig. 3. Modulus of elasticity depending on pressure and volume fraction

On Figure 3 is outlined the theoretical value of water modulus is called a theory 1 . In the above equations is marked as $K_{r e f}$ and for calculation is specified value $K_{\text {ref }}=2.1 \cdot 10^{9} \mathrm{~Pa}$. From Figure 8 it is evident that peak pressure in the hydraulic shock to move around $200 \mathrm{kPa}$ (relative pressure), while the Figure 3 shows that when the pressure is to change modulus of liquid elasticity is very significant. Therefore, this parameter must be included in the calculations.

The value of elastic modulus specified from experiments and designated by the RLC resistance in the range $(200 \div 400) \mathrm{kPa}$ (absolute pressure) corresponds approximately to the curve with consideration of air volume fraction $\alpha=0.01[3,7,8]$.

\section{Possible solutions}

Based on the evaluation, depending on the density from pressure and determination of modulus of liquid elasticity I defined these alternative solutions:

1. Theory 1

$$
\rho=\rho_{r e f} \cdot\left(1+\frac{p_{r e l}}{K}\right)=998 \cdot\left(1+\frac{p-98000}{2.1 \cdot 10^{9}}\right)
$$

2. From experiment

$$
\rho=\rho_{r e f} \cdot\left(1+\frac{p_{r e l}}{K}\right)=998 \cdot\left(1+\frac{p-98000}{62172146}\right)
$$

3. From RLC resistances

$\rho=\rho_{r e f} \cdot\left(1+\frac{p_{r e l}}{K}\right)=998 \cdot\left(1+\frac{p-98000}{114130435}\right)$

4. Theory 2

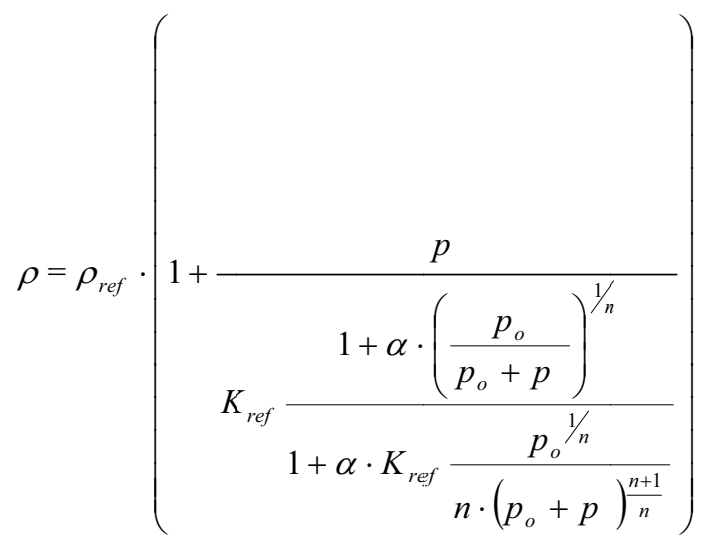

After substitution

$$
\rho=980 \cdot\left(1+\frac{p}{2.1 \cdot 10^{9} \frac{1+0.001 \cdot\left(\frac{98000}{98000+p}\right)^{1 / 1.4}}{1+0.001 \cdot 2.1 \cdot 10^{9} \frac{98000^{1 / 1.4}}{1.4 \cdot(98000+p)^{\frac{1.4+1}{1.4}}}}}\right)
$$


5. From literature [5]

$$
\rho=\frac{p}{(0.000999999 \cdot p+0.099249)}
$$

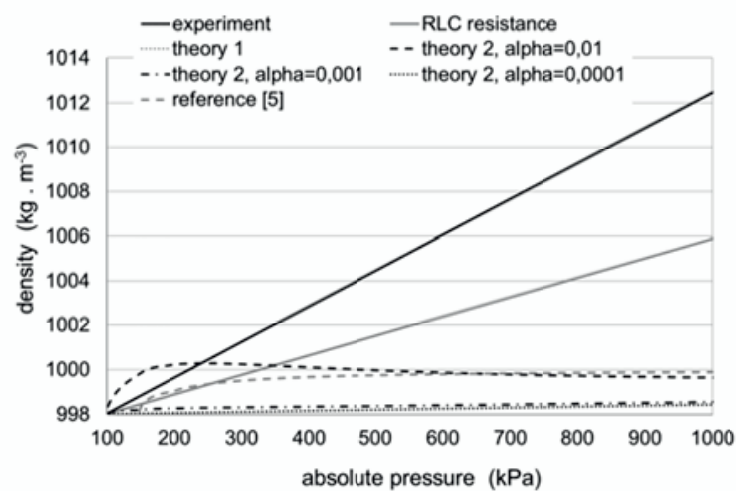

Fig. 4. Specific weight of water depending on the pressure and volume fraction

On Figure 4 is shown the dependence of specific weight for water on pressure. According to the above-described variants depends the density on the modulus of liquid elasticity Most accurate is theory 2 because expresses dependence on the volume fraction of air in the liquid (water). Changing the water pressure is most important when considering modulus of liquid elasticity determined from experiment.

\section{Modeling of hydraulic shock}

Hydraulic shock can be modeled in different programs. If we take into account in calculating the modulus of elasticity, Matlab SimHydraulic can be used. The Fluent program in which the simulation is carried out, the density reflects modifications modulus of liquid elasticity. For solution has been used only program Fluent.

Generalized Rayleigh - Plesset equation for bubble dynamics (time-dependent pressure and size of bubbles) in form

$$
\begin{aligned}
& \frac{p_{\text {vap }}(t)-p_{\infty}(t)}{\rho_{l}}=R_{b} \frac{d^{2} R_{b}}{d t^{2}}+\frac{3}{2}\left(\frac{d R_{b}}{d t}\right)^{2}+ \\
& +\frac{4 v_{l}}{R} \frac{d R_{b}}{d t}+\frac{2 S}{\rho_{l} R_{b}}
\end{aligned}
$$

for certain value of pressure $p_{\infty}(t)$ can be solved and bubble radius $R_{b}(t)$ can be determined (in case of the pressure value in bubble is known). This equation was used by scientists like Rayleigh and Plesset equation in simplified form (the term of surface tension and the term of viscosity were ignored and higher order derivatives). For more details, please see [6, 7]. Common differential equation (17) has been too difficult to be applied into a multiphase flow model. That is why the first order approximation has been explain in this case:

$$
\frac{d R_{b}}{d t}=\sqrt{\frac{2}{3} \frac{p_{v a p}(t)-p_{\infty}(t)}{\rho_{l}}}
$$

Mathematical model is defined for multiphase mixture consisted from water and vapour eventually air. For multiphase flow simulation the Mixture model is used. This model is advisable, when the velocity of individual phase translation differs. Model provides phase changeover, for this occasion the volumetric fractions of phases are defined.

Continuity equation for the mixture has the form

$$
\frac{\partial \rho_{m}}{\partial}+\frac{\partial\left(\rho_{m} u_{m, j}\right)}{\partial x_{j}}=0
$$

where $u_{m, j}$ is the mass-averaged velocity and $\rho_{m}$ is the mixture density defined by expression.

$$
\rho_{m}=\sum_{k=1}^{n} \alpha_{k} \rho_{k}
$$

$\alpha_{k}$ is the volume fraction of phase $k$ and $n$ is the number of phases.

The main liquid - water contains small amount of non-condensable gas - vapour (dissolved) [6]. This gas can has significant effect on the cavitation area due to expansion at low pressures. The model is assumed a mixture of the liquid (water) phase and gas phase. The gas phases consist of the water vapour and noncondensable gas, which was insignificant.

The density of the mixture $\rho_{\text {is calculated as }}$

$$
\rho=\alpha_{v} \rho_{v}+\left(1-\alpha_{v}\right) \rho
$$

where $\rho_{l}$ is the density of the liquid (water), $\rho_{v}$ is the density of the vapour, $\alpha_{l}=1-\alpha_{v}$ is the volume fraction of the liquid (water) and $\alpha_{v}$ is the volume fraction of the vapour. The relationship between the mass fraction and volume fraction is:

$$
\alpha_{k}=f_{k} \cdot \frac{\rho}{\rho_{i k}}
$$

where $f_{k}$ is the mass fraction of the phase $k, \alpha_{k}$ is the volume fraction of the phase $k, \rho_{k}$ is the density of the phase $k$.

\subsection{Geometry and network of modeled area}

Geometry is 2D axially symmetric, therefore is sufficient to model only one half of the geometry. Computational cells are shaped like a rectangle. Computational cells are evenly distributed, the number of cells is 3200 . 


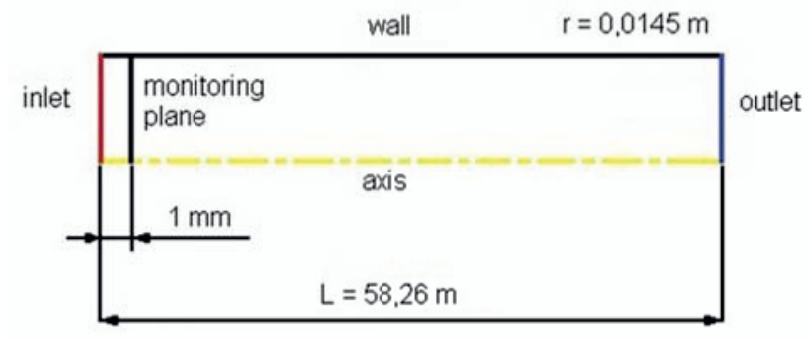

Fig. 5. Scheme of the modeled area - network

\subsection{Physical properties}

Modeling was carried out with an expected constant temperature of flowing medium $26{ }^{\circ} \mathrm{C}$, i.e. $299 \mathrm{~K}$ and temperature dependency is not considered. Air density is calculated from the equation of state (ideal-gas). The viscosity of air is defined by value $1.7894 \cdot 10^{-5} \mathrm{~kg} \cdot \mathrm{m}^{-1} \cdot \mathrm{s}^{-1}$. Air density is defined using according to options described in Chapter 4 (depending on modulus of liquid elasticity and piping). Water viscosity is defined by value $0.001 \mathrm{~kg} \cdot \mathrm{m}^{-1} \cdot \mathrm{s}^{-1}$.

For steam are default values retained i.e. density is $0.5542 \mathrm{~kg} \cdot \mathrm{m}^{-3}$ and viscosity is $1.34 \cdot 10^{-5} \mathrm{~kg} \cdot \mathrm{m}^{-1} \cdot \mathrm{s}^{-1}$.

\subsection{Boundary conditions}

For modelling is used laminar model, since the maximum $R e=26970$ and during closure will occur the reduction of speed, so Re number will decrease. Further the mixture model is used, since it is multi-component flow - the fluid consists of water, air and possibly steam. Boundary conditions are intended for $\alpha=0.001$ (volume fraction).

Table 2. Constant boundary conditions

\begin{tabular}{|c|c|c|c|}
\hline $\begin{array}{c}\text { inlet - Mass- } \\
\text { flow-inlet }\end{array}$ & Mass flux & Water & $928.6916 \mathrm{~kg} \cdot \mathrm{m}^{-2} \cdot \mathrm{s}^{-1}$ \\
\cline { 2 - 4 } $\begin{array}{c}\text { Outlet }- \\
\text { pressure-outlet }\end{array}$ & $\begin{array}{c}\text { Gauge } \\
\text { pressure }\end{array}$ & Mixture & $0.00117 \mathrm{~kg} \cdot \mathrm{m}^{-2} \cdot \mathrm{s}^{-1}$ \\
\hline
\end{tabular}

Table 3. Time-varying boundary conditions on the input Mass-flow-inlet

\begin{tabular}{|c|c|c|c|c|}
\hline Time & $\begin{array}{c}\text { Mass flux } \\
\text { of mixture }\end{array}$ & $\begin{array}{c}\text { Mass flux } \\
\text { of water }\end{array}$ & $\begin{array}{c}\text { Mass flux } \\
\text { of air }\end{array}$ & Note \\
\hline$(\mathrm{s})$ & $\left(\mathrm{kg} \cdot \mathrm{m}^{-2} \cdot \mathrm{s}^{-1}\right)$ & $\left(\mathrm{kg} \cdot \mathrm{m}^{-2} \cdot \mathrm{s}^{-1}\right)$ & $\left(\mathrm{kg} \cdot \mathrm{m}^{-2} \cdot \mathrm{s}^{-1}\right)$ & \\
\hline 0 & 928.69275 & 928.6916 & 0.00117 & \\
\hline 9.6 & 928.69275 & 928.6916 & 0.00117 & $\begin{array}{c}\text { Start of } \\
\text { closure }\end{array}$ \\
\hline 9.8 & 0 & 0 & 0 & $\begin{array}{c}\text { End of } \\
\text { closure }\end{array}$ \\
\hline 25 & 0 & 0 & 0 & \\
\hline
\end{tabular}

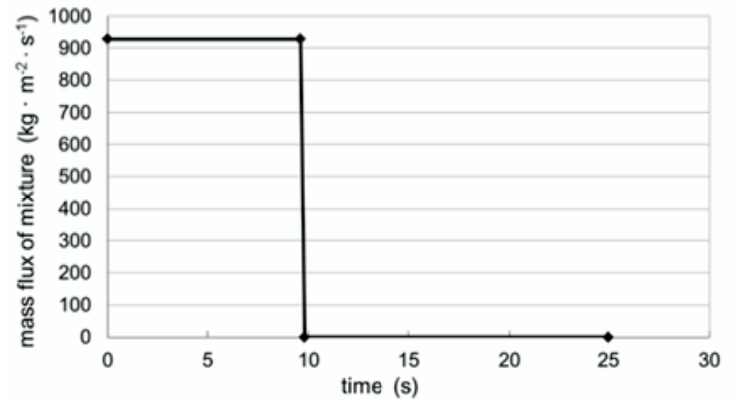

Fig. 6. Variable boundary conditions

Two variants are addressed - without cavitation and with cavitation. The piping is considered to be horizontal, without friction and local losses.

When thinking of cavitation the Schnerr Schauer cavitation model is used. The cavitation model is defined by the bubble number density whose value was determined $1 \mathrm{e}+13$ and vaporization pressure, the value of which is $3540 \mathrm{~Pa}$.

\section{Modeling results compared with measurement}

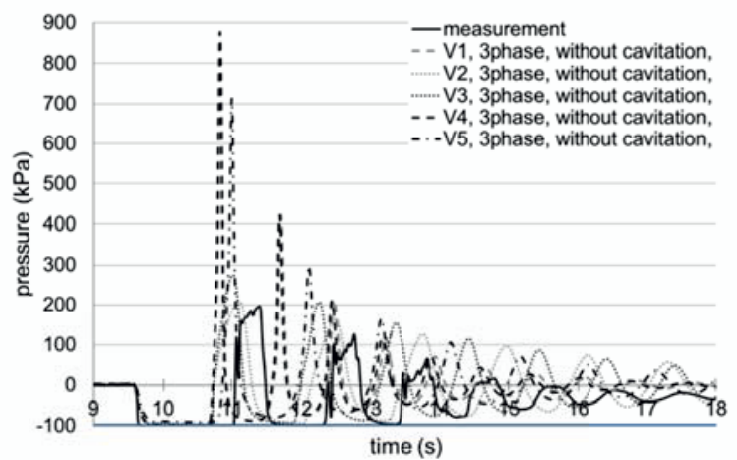

Fig. 7. Course of pressure during hydraulic shock, modeling without cavitation

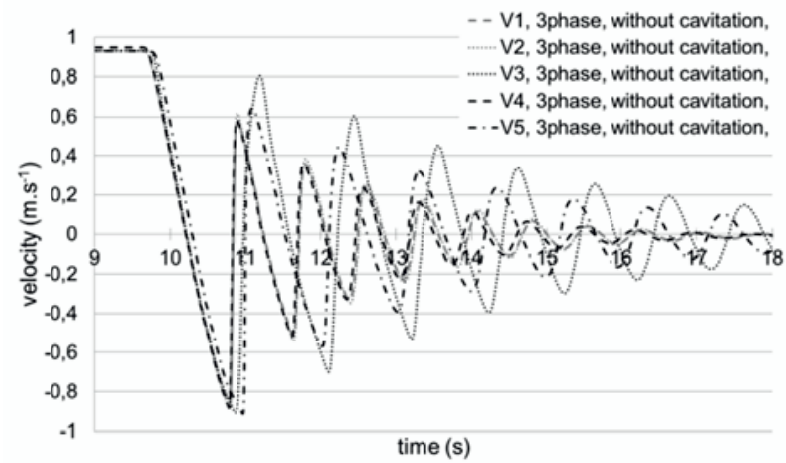

Fig. 8. Course of speed during hyidraulic shock, modeling without cavitation 


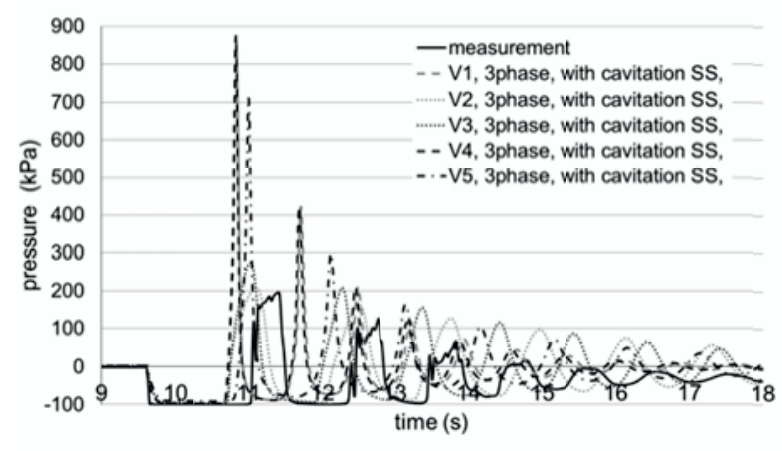

Fig. 9. Course of pressure during hydraulic shock, modeling with cavitation

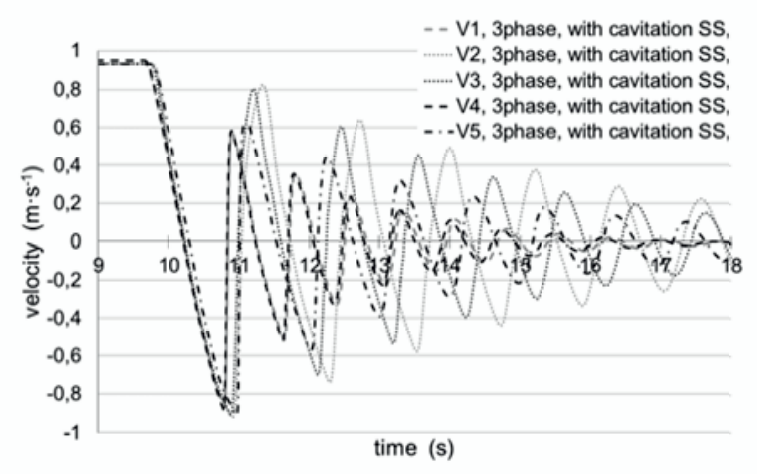

Fig. 10. Course of speed during hydraulic shock, modeling with cavitation

\section{Conclusion}

From the graphs in Figure $7-10$ it is evident that most suitable variant of modeling is V2, respectively. V3. In both, there is a slower absorption of pressure and velocity.

The best variant for determining the density is according to option 2, which is based on determination of modulus of liquid elasticity from the experiment. It can be said that the modulus of elasticity determined from experiment involves flexibility of wall piping and partly air content in the water. This method, however, can not accurately determine the volume of air in the water.

Another very good option to determine the dependence on pressure is variant 3 , which is based on the RLC resistance. In this variant is included modulus of elasticity piping wall with consideration of ideal fluid. With this solution results can be used to determine the air content in the liquid. Individual air content can be entered into the boundary conditions.

From graph in Figure 4 shows that variant 2 and 3 (density depending on the pressure) are much more significant changes in in these than for others. As the pressure range during hydraulic shock from $(-100) \mathrm{kPa}$ to $250 \mathrm{kPa}$ (relative) is the density change large and affects other calculation.

Modeling of hydraulic shock with cavitation does not bring very different results and is more time consuming.

\section{Acknowledgements}

The paper has been suppiorted by project GACR 101/09/1715 „Cavitating Vortical Structures Induced by Rotation of Liquid.

This paper has been elaborated in the framework of the project Opportunity for young researchers, reg. no. CZ.1.07/2.3.00/30.0016, supported by Operational Programme Education for Competitiveness and cofinanced by the European Social Fund and the state budget of the Czech Republic.

\section{Literature}

1. D. Himr, Experimental Fluid Mechanics (EPJ Web of Conferences 2013), 45 (2013) p. 275280 .

2. J. Noskievič, Mechanika tekutin. 354 p. (1987).

3. Software Matlab Simulink, SimHydraulic (user manual).

4. W. Henry, Philosophical Transactions of the Royal Society of London. 93, (1803)

5. D. Himr, V. Habán, F. Pochylý, Engineering mechanics 2009. p. 393 - 401, (2009)

6. Software Ansys Fluent Inc Fluent 12.16- User's guide (2009)

7. M. Kozubková, Matematické modely kavitace a hydraulického rázu. 130p. (2009)

8. L. Hružík, M. VAS̆INA, A. BUREČEK Experimental Fluid Mechanics (EPJ Web of Conferences 2013), 45, No. 01041 (2013)

9. R. Olšiak, M. Mlkvik, B. Knížat, 15th International symposium on Flow Visualiztion. (2012) 